\title{
An Integrated Multi-year Iterative and Service-oriented Capstone Project
}

\section{Dr. Joyce Blandino P.E., Virginia Military Institute}

Dr. Joyce Blandino received her Ph.D. in Biomedical Engineering from the University of Virginia. She is currently an Associate Professor in the Department of Mechanical Engineering at the Virginia Military Institute. She previously taught in the Biology Department at Washington and Lee University. Before that, she was a faculty member at James Madison University.

\section{Col. Jon-Michael Hardin P.E., Virginia Military Institute}

Jon-Michael Hardin, Ph.D. Professor and Department Chair in the Mechanical Engineering Department at the Virginia Military Institute. He has degrees in mechanical engineering and theoretical and applied mechanics from the University of South Carolina and the University of Illinois at Urbana-Champaign, respectively. His areas of research interest include engineering education/pedagogy and engineering mechanics applications. 
An Integrated Multi-year Iterative and Service-oriented Capstone Project 


\begin{abstract}
s
The purpose of this paper is to discuss and document the parallel, but different, processes the authors developed in conducting an integrated multi-year iterative and service-oriented capstone project to design and fabricate a low-cost transtibial prosthetic limb.
\end{abstract}

Capstone projects typically span one to two semesters. In many cases, a single student design group is only able to concentrate on the design aspects of a capstone design project conducted within a single semester. In two-semester projects, the second semester typically provides the same student design group the necessary time to build and test the design they completed during the first semester. Unlike these typical capstone projects, the authors' prosthetic capstone design project spanned four years and involved multiple student design groups. Students in the first-year group conducted a feasibility study and built a basic prototype of the design. The iterative design process then started with the second-year group since their design constraints were derived from the results from, and client feedback received by, the first-year group. The refined design from the year-two group, in turn, became the design constraint for the year-three group and the year-three design became the design constraint for year-four group. Additionally, each year, an iterative design process was also performed by that year's student design group. In this multi-year project, students learned both the short- and long-term iterative processes of product design and development. One of the challenges of doing a multi-year project was to maintain the continuity of the project since a different group of students was involved each year.

In addition to the challenges related to conducting this multi-year design project, there were quite different challenges presented by the project being a service-oriented project. Many capstone projects come from industry where students receive technical feedback on their design from engineers as part of the iterative design process. However, in service-oriented projects such as the authors' project, students typically receive design feedback from the client. Therefore, one of the many challenges the authors addressed was helping their student design groups to convert the ambiguity inherent in that client feedback into technical changes in their design as part of the iterative design process.

In this paper, the authors discuss and document the processes they developed to handle these challenges related to their integration of a multi-year multi-team iterative and service-oriented capstone design project.

\title{
Introduction
}

It has been well documented that a capstone design course has been instituted in many engineering programs since late 1990s [1]-[3]. The changes of the capstone design practices over the past 20 years were captured in the "2015 Capstone Survey results" published by Howe et al [4],[5]. The capstone design survey separated the responses into eight categories: "Respondent Profile, Course Logistics, Pedagogy, Faculty and Students, Project and Teams, Expenses and Funding, Sponsors, and Experience and Opinion." Overall trends showed that there was an increase in 2-semester capstone design courses than previous years and more courses were provided in conjunction with the design project class. The emphasis of "product versus process" remained at the same level over the years since "the majority of respondents either weighted the two equally or emphasized process". The data also showed that "the 
expectations for student time commitment have increased" from 4-6 hours (median) to 7-9 hours (median). The average number of members in the team was 3 to 4 students which was the same as before and each team worked on a single project. There was a slight increase in team size of 4-6 students overall. The funding source for projects remain unchanged for the past 20 years. They were from department, institution, and sponsors to pay for project supplies and hardware, and some software. The majority of projects was still from industry/government, followed by faculty research. However, there was "an increase in entrepreneurial projects, as well as the emergence of service-learning projects" [5].

A capstone design course allows students to gain experience through the design process by applying knowledge learned from course work in the curriculum to solving a real-life problem. Specifically, the learning of the design process can be modelled by the "Ways of Thinking" framework introduced by Lande and Leifer [6], which consists of "Design Thinking, Engineering Thinking, Production Thinking, and Future Thinking." The path that students used for the project described in this paper centered on the Design Thinking and Engineering Thinking framework. This paper discusses and documents the parallel process of a multi-year multi-team iterative and service-oriented project. This project is unique in that it is a combination of longitudinal iteration and service learning. The implementation of this project was different from traditional capstone design projects in that the project was multiyear and multi-team. It is more common to have the same group of students working on the project for 1, 2, or 3 semesters [7]-[11]. In addition to the traditional engineering aspect of the project, our project incorporated the service-learning component, which provided additional challenges to the students' thinking in the design process. One component of any design process is to have several iterative processes so as to be able to develop a workable product [7]-[11] for the sponsor/user. According to Cheville [7], "The most important factor is the ability of teams to perform multiple iterations of the design project. Design projects that are not amenable to multiple iterations reduced students' chance of success." In addition, as discuss within the framework of "Ways of Thinking" [6], students "benefits from repeated iterations between Design thinking and Engineering thinking". The distinctiveness of the authors' multi-year multi-team iterative project is that the iterative process was also applied from one team to the next and from one year to the next, without any overlapping of students in each team as opposed to the same group of students working on the same project for many semesters.

The authors' multi-year iterative project is also different from the Vertically Integrated Project (VIP) and Design Competition projects. The VIP model's central theme " is that undergraduates' work supports the faculty mentor's research, yielding deep long-term faculty engagement." [12]. The VIP projects are typically multidisciplinary and multiyear and involve students from freshmen to seniors [12]-[16]. Upper level students serve as mentors to lower level students. When students graduate, the remaining students in the program became mentors to the newly recruited lower level students. This structure ensures the continuation of the project and the sustainability of the VIP program. On the contrary, for our multi-year multi-team project, there was no mentoring from student to student within the group since they were all seniors. At the completion of their project, students graduated and therefore, no students remained to teach the incoming students about the project or best practices of the design process. This project is also different from a Design Competition project. In a design competition project, students' main focus was on the completion of the product and less on the process of design [17], 
whereas in this project the focus of the students was to achieve a balance between process and product. For example, Poynter et al [17] described that the competition design project scope for the Society of Automotive Engineers (SAE) student competition was to modify a snowmobile to be more "environmentally friendly that can be operated in sensitive areas". Design criteria (amount of noise levels, fuel efficiency, and reduction of emission) were specified by the competition. Therefore, students' focus was on the final product, not so much as the design process. The authors' multi-year service-oriented project was more open-ended than a design competition project and students had to find a balance between design process and product.

As reported from the 2015 Capstone Design Survey [5], many schools employed servicelearning projects as their capstone design course. The purpose of a service-learning project was for students to "grow their concept of community" [18] and "try to give back to the community" [19]. There are differences between working on an industrial-sponsored project and a serviceoriented project. According to Brackin and Gibson [20], "service-learning projects require different skills from an industrial sponsored project. With industrial projects, the sponsors are usually engineers who can explain their problem in technical language." For service-oriented projects, the challenge was to communicate with non-technical people and the project was more open-ended, meaning the project statement was not technically defined [20]-[23]. Students learned to interpret the needs of the client and translate those needs into technical constraints for the design. In general, students participating in service-oriented project were found to be more committed to the project as they wanted to help someone [20]-[23].

One of the challenges of multi-year multi-team project is to ensure a smooth transition from one team of students to different students in the next team who work on the same project. According to Owens, Morris and Hall [8] and Johnson and Alvarado [10], documentation and effective communication are the key for successful completion of the project. The creation and use of shared computer website [8],[10], where all information from the iterative processes such as codes, CAD model, prototype information, and all documentations and final report were stored and could be retrieved by all students who worked on the project, are a must.

There are many factors that affect the effectiveness of doing a multi-year multi-team iterative service-oriented project. The purpose of this study is to explore the practicality of implementing a combination of longitudinal iteration and a multi-year multi-team service-oriented project. The following provides the background and reason for doing this project, the iterative steps used for each team/each year, the design process employed, and challenges of managing the project at each phase. A "lessons learned" from the experience implementing this project is summarized and future work is also provided at the end of this paper.

\section{Background}

A low cost transtibial prosthetic limb is desirable since the cost of prosthesis varies, from as low as $\$ 5000$ to over $\$ 50,000$ [24]. The high cost of the prosthesis is due to (1) each prosthesis is custom made for the user, and (2) the materials used for the prosthesis and the design of the prosthesis are highly dependent on the needs of the user such as dwelling, daily activities, and health [25]. Also, the prosthetic limb is typically replaced every 3-4 years due to wear and tear 
as well as changes in shape of the amputated limb due to weight gain or lost. The design of the low cost transtibial prosthesis limb is, therefore, an ideal service-oriented project and it can fulfill the ABET criteria 3 student outcomes [26].

The transtibial prosthetic limb is composed of foot, ankle, shank (pylon), and socket [27]. Each component requires comprehensive design and analysis. It has to be built using materials that are easily available and inexpensive. The project would take several years to complete. The capstone design teams in the authors' department have a small number of students and each project is limited to have a maximum of three students. In general, each group of students work on different types of projects. It is just not possible to design, build, and test a 'robust' prototype within a year with only one three-person team. Therefore, the authors decided to have students work on the project in stages with different team members from one year to the next. Each team would still fulfil the requirement of capstone design course objectives: design, analyze, build, and test the product.

\section{Methodology}

\section{Client}

The client was a transtibial amputee (amputation below the knee) and was very excited to volunteer to serve as the client and test subject for the project. The client felt it was important for engineering students to learn through the design process and to apply their engineering skills to design and build the prosthetic limb. It was also important to the client to be able to convey to the students the challenges presented by life as an amputee and the problems they encountered. The client did not have any issues working with the students over many years. The client lives in Rockbridge County, VA. An IRB approval from the Virginia Military Institute (VMI) Institutional Review Board was obtained before recruiting the client. The testing of the prosthetic limb was conducted in the Biomechanics Lab at VMI.

\section{Research Site and Student Sample}

All seniors in the Mechanical Engineering department at VMI, a small undergraduate-only university, were enrolled in the capstone design class. The class size varied from 24-34 depending on the year. Students were divided into teams of 1-3 students for each capstone design project per year. Students chose to work on this project.

\section{Research Process}

Each team was required to utilize the iterative process with feedback from the client. Each year's team met with the client at the beginning and end of the project. The feedback from client and from the team would be provided for the next team and was used to develop the new design constraints. This next year's team then used the new design constraints and client feedback to redesign, build, and test. This process was repeated for each team until the whole project was completed. Each team met with the faculty advisor weekly. Each year's team was required to write a final report detailing the whole process of design concepts, dimensions of design components, materials properties, CAD model, finite element analysis and results, testing results, and suggestions for improvement. In addition, all CAD models, finite element analysis set up and results, and the final report were deposited in the shared website specifically created for this project. The development and management of each stage of the project are described below. 


\section{Iterations}

\section{Year 1: Feasibility Study}

Design constraints: The first team was tasked to develop a basic design of the prosthetic limb. There were four main constraints for the design: (1) it had to be inexpensive; (2) it had to be able to support the weight of the test subject; (3) parts used were easily replaceable; and (4) it had to be simple to build.

Design process: Before meeting with the client, the team members educated themselves by doing a thorough research in prosthetic design and problems associated with amputees using prosthesis. They wrote down questions to ask when they had their first meeting with the client and what type of measurements to take from the client for the initial design. The client provided "candid" information on what caused the amputation, how the client's life changed since the accident, how the prosthetic limb affected daily activities, and problems with the prosthetic limb. Students then took measurements from the client. These included measuring the dimensions (length, width, and height) of client's normal foot, length of normal leg, and length and circumference of the stump. The measurement from the client's own prosthetic limb was also recorded for later comparison with the test results from the students' low cost transtibial prosthetic limb.

Because of the complexity of the socket, the team concentrated on three different design components first: foot, ankle, and pylon. After careful analysis of the advantage and disadvantage of several design concepts for each component, the team narrowed down to the following design as shown in Figure 1.

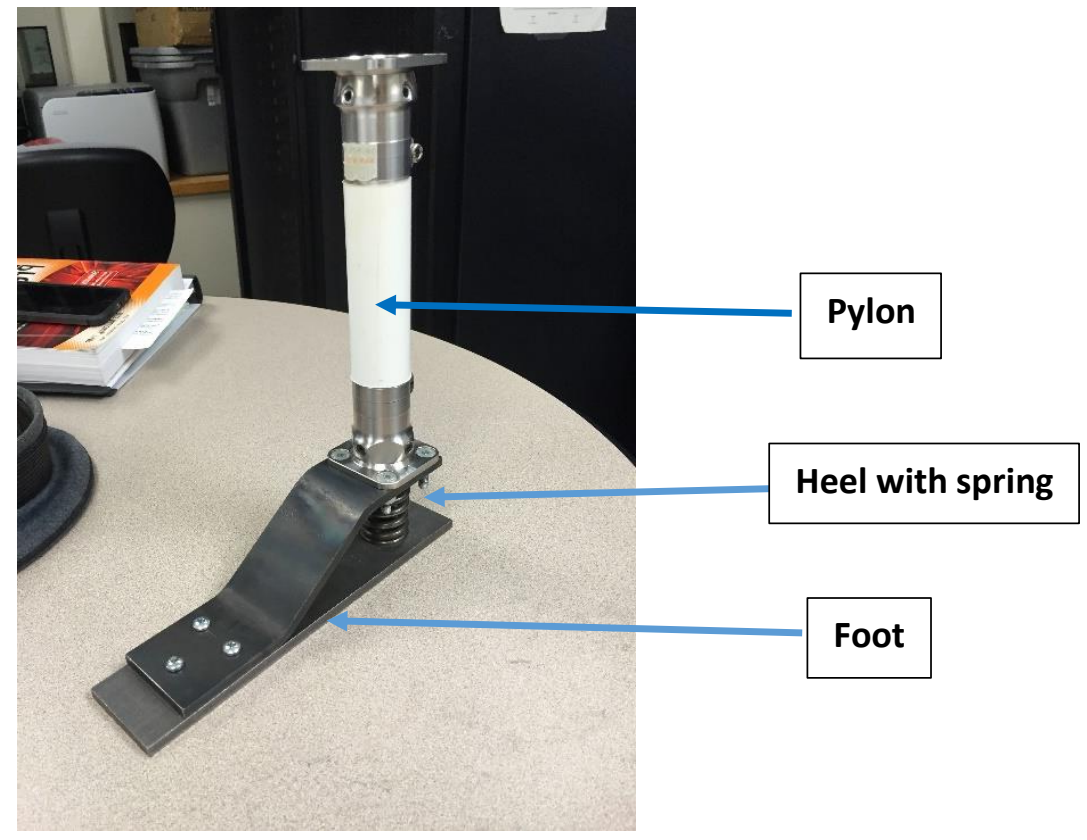

Figure 1: Preliminary prototype of prosthetic limb. 
The foot design included an elevated heel on flat plate. A spring was inserted at the heel to provide some cushioning at the foot segment. To provide structural support, low cost 1018 steel was used as the material of the foot. The pylon was a straight pipe made with an inexpensive polyvinyl chloride (PVC) that can be purchased from any home improvement stores. The connectors at the top and bottom of the pylon utilized inexpensive commercially available products. All design components were generated and assembled using SolidWorks modeling software. The completed prosthetic limb model was then imported into ANSYS for finite element analysis (FEA) of stress and deformation under static load conditions similar to those applied in real life. A separate buckling analysis was performed on the pylon model in ANSYS. Once the FEA results demonstrated the stress and deformation were within acceptable limits, a prototype was built. The built prototype was then subjected to static load testing in the laboratory to ensure the prosthetic limb could sustain the weight of the client. The prototype, including the designed foot and pylon, was then tested on the client. Figure 2 shows the client fitted with the preliminary prosthetic limb standing on the force platform.

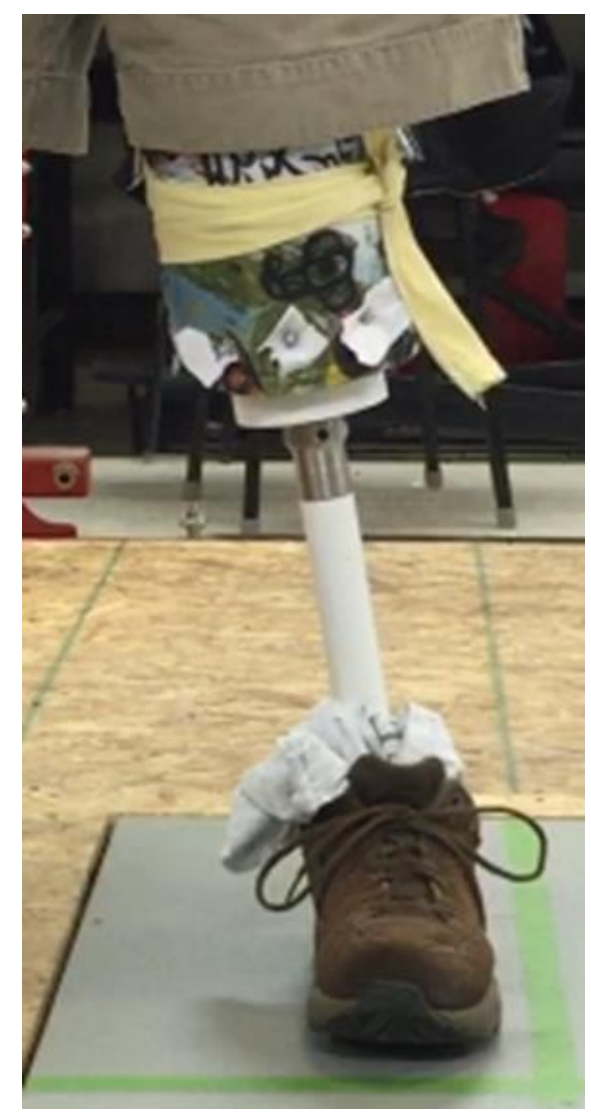

Figure 2: Preliminary prosthetic limb fitted to client's stump on force platform.

Results: There were many challenges and lessons learned from this project. This valuable information provided the basis for the design constraints for the follow-on teams. At the beginning, the Year-1 team students felt overwhelm by the scope of the project. There were many elements involved in the design, analysis, and fabrication for each component that required more guidance from the faculty mentor. Therefore, the process was time consuming for both the faculty advisor and the Year-1 team. At the end, the team was able to design and fabricate a 
feasible working prosthetic limb. They also made several recommendations for the follow-on teams. First and foremost, they recommended that each later team only work on a singlecomponent design project. Second, they recommended a redesign of the foot/ankle since the construction of the heel plate of the foot/ankle was time consuming. This recommendation would become the design constraint for the Year-2 team who would work on the refinement of the foot/ankle. Third, they recommended making an adjustable pylon based on client testing. In fact, the feedback from the client was that the client felt 'wobbly' during walking on the prosthetic limb and did not feel comfortable with the pylon made with the PVC pipe. Thus, the redesign of a less 'wobbly' adjustable pylon would become the design constraint for the Year-3 team. Fourth, the socket would also need to be redesigned. Because of time constraints, the Year-1 team did not design the socket, but rather, with the help of the faculty advisor, the team constructed a temporary socket using PVC fitting and flexible polyethylene sheet that could accommodate stumps with varying size. The feedback from client from the two fittings was that the socket component needed to be more comfortable and fit tighter. A better socket design would, therefore, be the design constraint for Year-3 team.

\section{Year 2: Refinement of foot/ankle}

Design constraints: The faculty advisor reviewed the Year-1 team's recommendation with Year2 team students. Based on the Year-1 team recommendation, the Year-2 group focused on a single-component design - the foot/ankle component. The group met with the client at the beginning of the semester to obtain client feedback about the original Year-1 prototype. The feedback from the previous year's group and from the client became the design constraints for the Year-2 group. The constraints were (1) to design a less rigid foot/ankle to allow for more rotational movement at the ankle for walking on a slight incline surface, and (2) to simplify the fabrication process.

Design process: The team came up with two designs for the foot/ankle component with simple construction. Figure 3 illustrates the two redesigns of the base providing a hinge ankle support and using either metal springs or rubber springs to provide some rotational movement around the ankle. Figure 4 shows the ankle and foot assembly. The material used was 1018 steel. Using the redesigned foot/ankle and the same pylon, connectors, and socket used in the preliminary prosthetic limb, both finite element analysis and static loading on inclined plane with the refitted prosthetic limb were performed. The prosthetic limb with the redesign foot/ankle was then tested on the client.

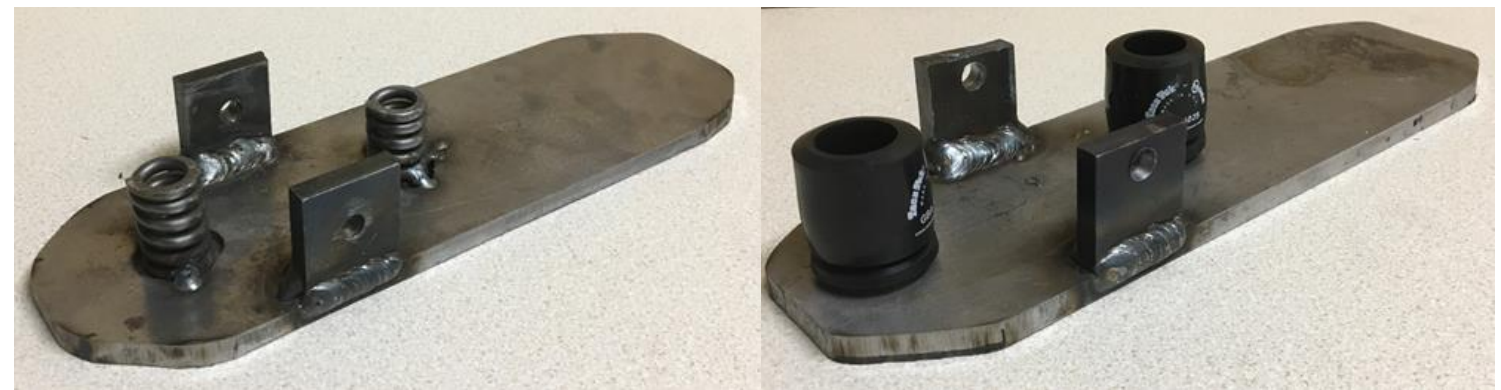

Figure 3: Base support with hinge supports and metal springs (left) and rubber springs (right) 


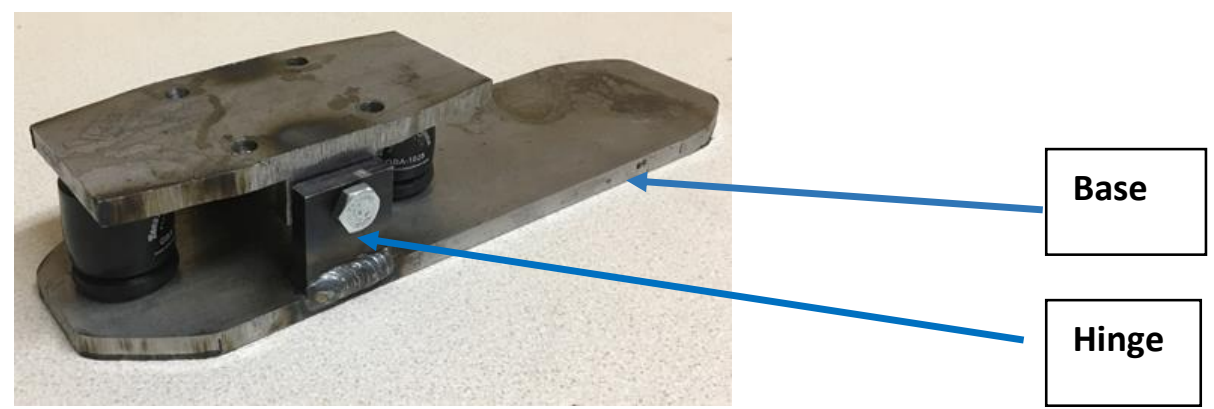

Figure 4: Ankle and foot assembly

Results: Due to students' access to Year-1 team information in the shared website, the Year-2 team managed the project in a reasonable time. They had a better idea about the whole project and the setup for modeling and ANSYS analysis. They did not require additional meeting time with the faculty advisor beyond the weekly schedule course meeting. From testing on the client, the feedback was that the metal spring assembly felt less stable to walk on as compared to the rubber spring. Recommendations from the Year-2 team were to design an adjustable pylon to reduce the fitting time for testing and a better socket for comfort and fitting, similar to the recommendations made by Year-1 team.

\section{Year 3: Refinement of pylon and socket}

Design constraints: In year 3, the faculty advisor reviewed the Year-1 and Year-2 recommendations with Year-3 team. Based on those recommendations two separate teams were created in year 3, with each team focusing on a single-component project: The Year-3A team focused on redesign of the pylon, while Year-3B team focused on the design for the socket. Both of the Year-3 teams met with the client to obtain feedback about the Year-2 prototype. The feedback from previous groups and from the client became the design constraints for the Year-3 groups. For the Year-3A team, the constraints for the pylon design were: (1) a different material for the pylon; and (2) the pylon needed to be adjustable. The constraints for the Year-3B team were that the socket: (1) be easy for the user to get in and out of; (2) be tight-fitted and yet not causing discomfort or pain on the user's stump; (3) allow movement at the knee joint; and (4) accommodate varies stump sizes.

Design process: During the testing of the original pylon design, the client felt 'wobbly' because the client perceived the PVC material of the pylon as 'unsafe'. Previous laboratory testing and ANSYS analysis demonstrated that the PVC pylon could support weight greater than that of the client. However, to address the 'unsafe' perception of the client concerning the original PVC pylon, Team-3A decided to use aluminum for the pylon since the team believed that a metal material might be perceived by the client as safer and because aluminum is inexpensive and lightweight. This was an important learning opportunity for the design team in working with human subject --- that although engineering analysis might prove that a design meets the engineering constraints, when working with a human client, client perception must be addressed. Figure 5 displays the final design with slip-lock mechanism for the pylon. Laboratory compressive test confirmed that there was no slipping of the adjustable part of the pylon under load. 


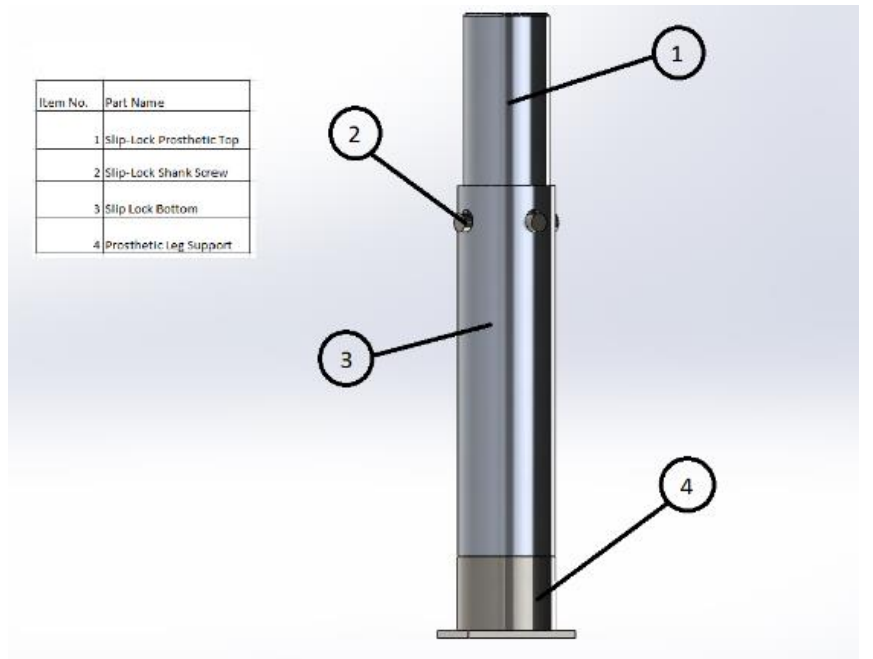

Figure 5: Slip-lock prosthetic shank

The Year-3B group had the more difficult task of designing the socket since that component requires a more custom design to match the unique configuration of the stump. Team-3B's design is shown in Figure 6. As can be seen in figure 6, the bottom of the socket used a PVC fitting. This fitting connects to the aluminum pylon designed by Team-3A. The bracket was made of aluminum, which was easy to cut and bend. Inexpensive high-density foam covered the inside bracket and bottom of the socket. Velcro straps secured the socket around the stump and allowed adjustment for various stump size. As shown in Figure 7, the low cost prosthetic limb fitted well to the client's stump.

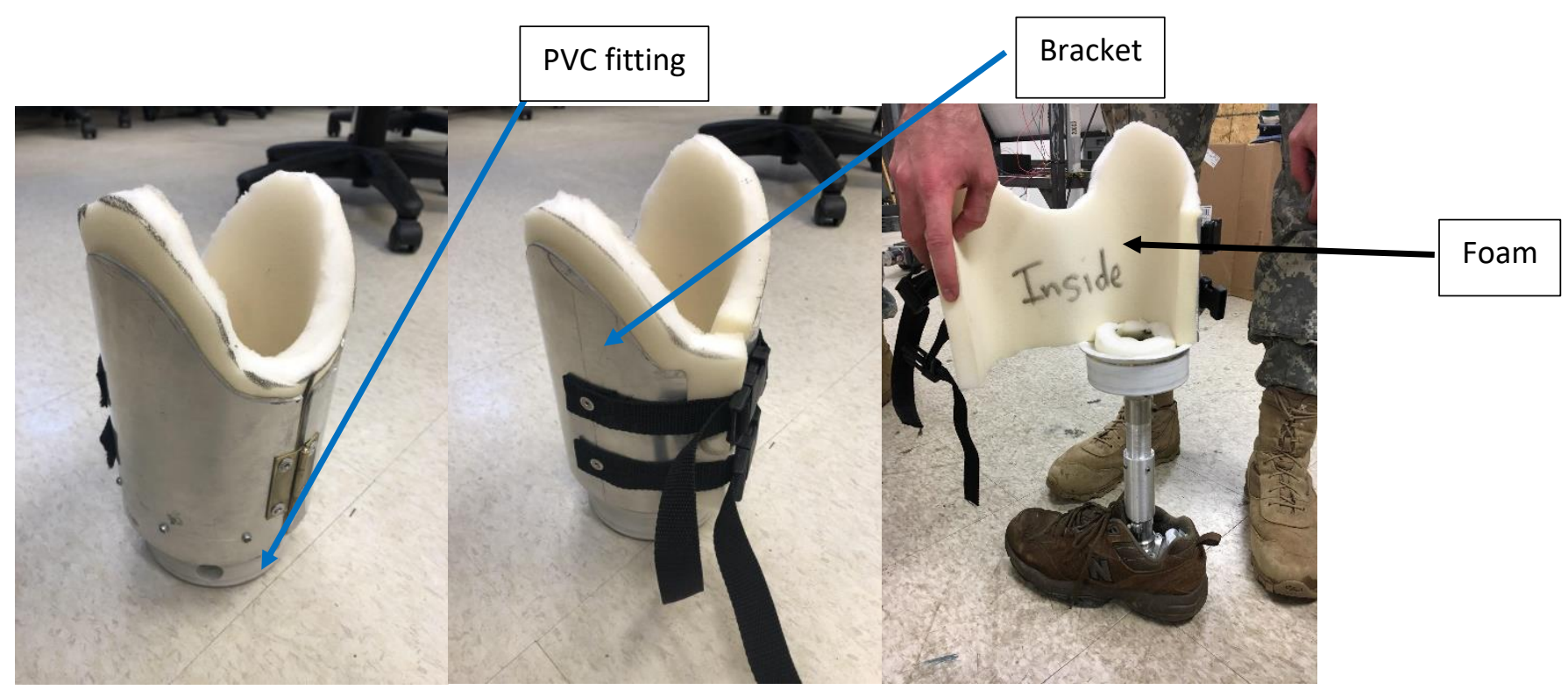

Figure 6: Socket and finished, redesigned model of the prosthetic of the front (left), rear (middle) and the inside (right). 


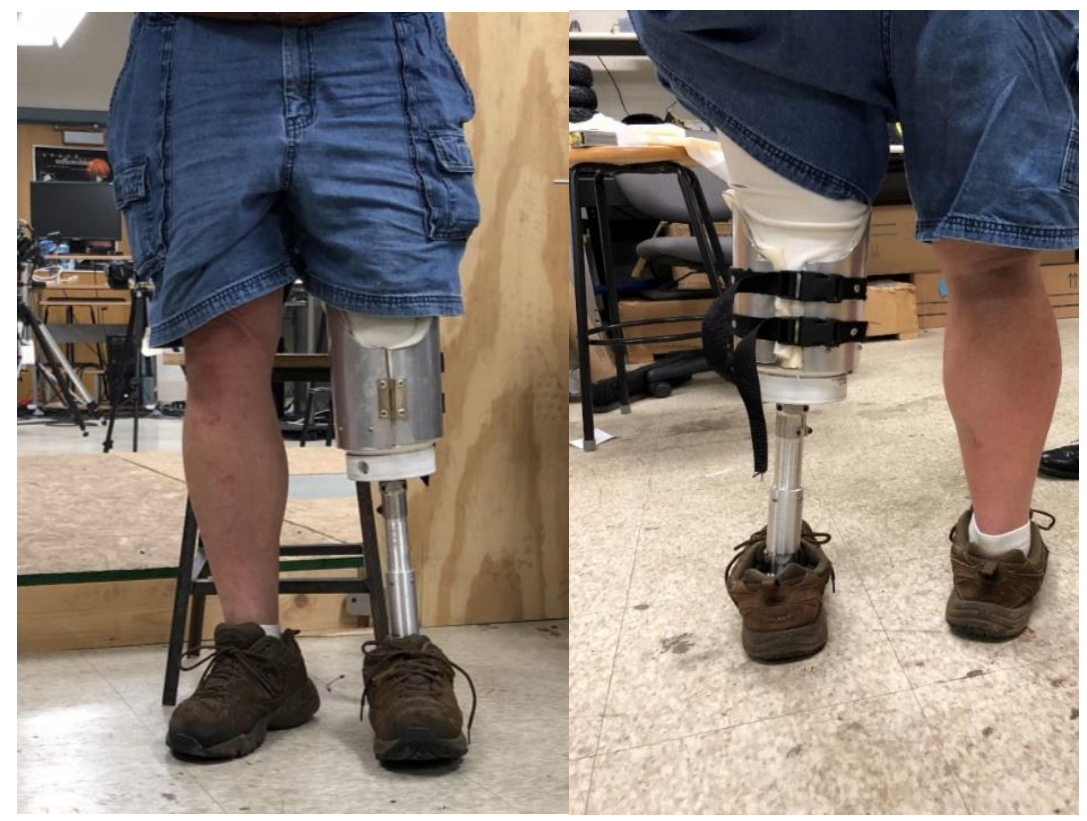

Figure 7: Final fitting and testing.

Results: The management of these two separate Year-3 groups was the same as that of the Year2 group. Both Year-3 groups had access to the files and data from previous groups in the shared website. Regular pre-set schedule weekly meetings were sufficient to manage the project. The first fitting on the client showed that the socket was small around the end of the stump because the team did not account for the extra sleeves the client wore over the stump. The bracket also needed to be higher with a cut out to provide side support and mobility at the knee joint. The client was satisfied with the aluminum pylon. With a redesign, an unexpected outcome came with the final fitting and testing with the client. The client could not walk straight forward with the prosthetic limb. It turned out that the stump of the client was not aligned axially downward as original assumed. At the initial meeting during year 1, the length of the stump was measured but not the angle of the stump from vertical. This provided a great learning opportunity for students in that it is not as straight forward when designing prototype for human use. Therefore, an extra year (year 4) was added to the project to incorporate the design of a universal movable joint compensator between the pylon and socket so that the subject could put weight on the prosthesis in any direction without hindering normal forward movement.

\section{Year 4: Further Refinement: joint compensator}

Design constraints: The faculty advisor reviewed the Year-3B team's recommendations with the Year-4 group. Based on those recommendations, the Year-4 group focused on designing a universal joint compensator between the pylon and the socket. Students met with the client and obtained feedback. Based on recommendation from the Year-3B group and from client feedback, the design constraint was that the joint compensator had to have adjustment in all three dimensions: front and back, left and right, and up and down. 
Design process: The team developed two different designs for the joint compensator. One was a ball-and-socket design and the other was link-lock design. Figure 8 shows both of these compensator designs and the entire prosthetic limb.

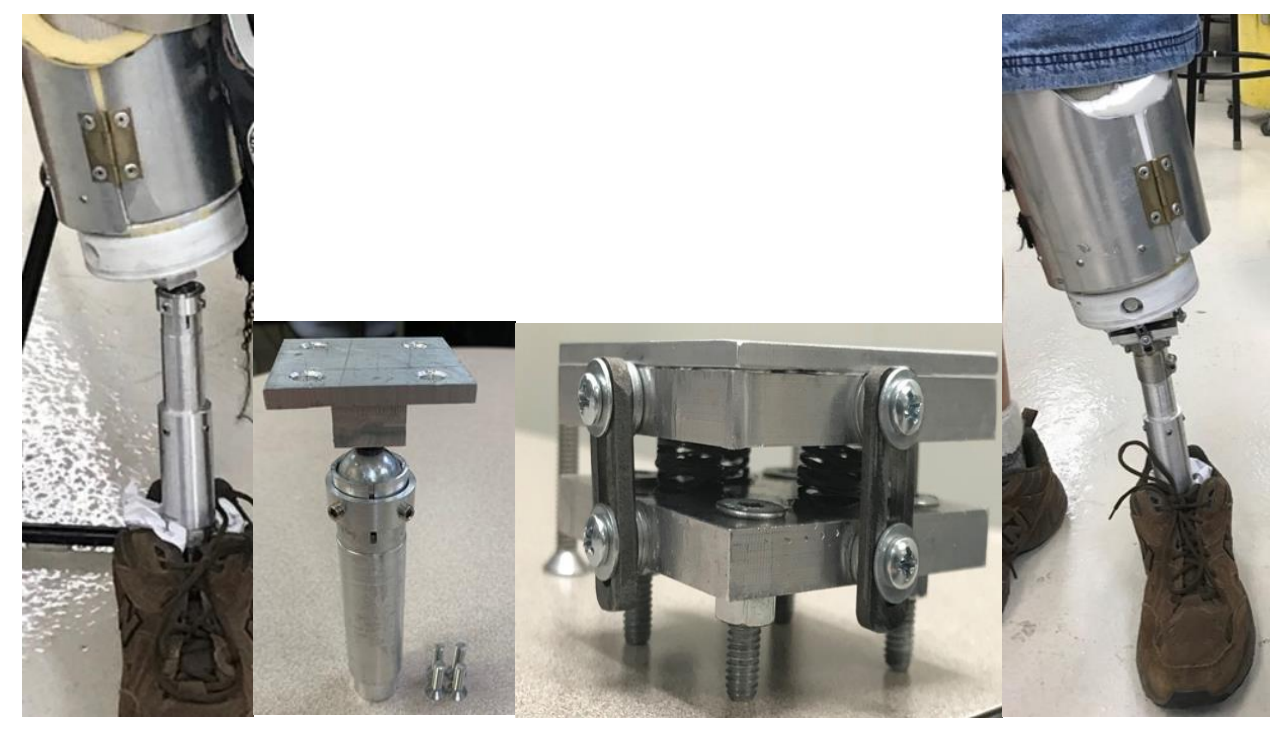

Figure 8: (left two) whole prosthetic limb assembly with the ball-and-socket joint compensator (right two) Link-lock joint compensator and the whole prosthetic limb assembly

Results: The management of this year 4 group project was similar to years 2 and 3 . Students worked on the project according to planned schedule. During the first testing, the client tested both design. However, there were some mechanical issues during testing. The client also mentioned a 'thicker' foam for the socket would increase comfort for the stump. For the second testing, a higher density foam was used in the socket to achieve better comfort and tightness around the stump. The client tested both design and preferred the link-lock design as it provided more stability. The client felt that the ball and socket design "unstable" because of the ball and socket connection.

\section{Conclusion/Lessons learned}

The purpose of this paper was to explore the practicality of implementing a multi-year multiteam iterative service-oriented capstone design project by designing a low cost transtibial prosthetic limb. The whole project spanned four years. The iterative process began with using the feedback from the Year-1 group and from the client as the basis of design constraints for the Year-2 group. The feedback from Year-2 group and from the client became the design constraints for two Year-3 groups. Likewise, feedback from Year-3 groups and from the client formed the basis of the design constraints for the Year-4 group. Each design group was made up of different students. The lessons learned are separated into two categories: (1) from the multiyear multi-team aspect and (2) from the service-oriented aspect.

\section{Lessons learned from the multi-year multi-team aspect:}

1. Having the same faculty advisor for the entire multi-year project duration is a prerequisite. This ensures a smooth transition from one group to the next, from one year to 
the next. It also reduces the time for 'relearning' the project if a new faculty were to take over in the middle of the project.

2. It is important to adhere to the scheduled weekly meeting between project advisor and team members to ensure proper progress is made in the project.

3. It is beneficial to have the same client throughout the four years. The client can provide feedback concerning the progress of the design as well as evaluate the work of the students.

4. All team members having access to a shared computer drive, which contains all the background materials, CAD model, ANSYS model set up and results, and final reports from previous teams. The follow-on team can read all the materials at the beginning and is, therefore, able to 'jump' into the project right the way.

5. Proper documentation and depositories of all files are a must at the end of each phase of the project.

The biggest challenge in doing a multi-year multi-team project is to ensure smooth transition from one team to the next. Owens, Morris and Hall [8] and Johnson and Alvarado [10] stated that documentation and communication are key for successful completion of the project. Our experience working on this project agrees and reaffirms this advice wholeheartedly as listed in items \#4 and \#5 above.

\section{Lessons learned from the service-oriented aspect:}

1. You have to learn to translate the client 'feedback' into engineering design. Since the feedback from client is always in non-technical terms such as 'wobbly', 'comfort', 'unstable', students need to think about exactly what those terms mean relative to making appropriate technical design constraints.

2. You have to take into account the client's 'perceptions' in the engineering design. For example, the client perceived the PVC pylon was unsafe even though technical analysis demonstrated it was a safe material to use. Therefore, a different material was chosen for the design.

3. You always have to expect the unexpected when designing for human use. The original plan for the project was to work on the foot/ankle, pylon, and socket component of the transtibial prosthetic limb. However, the stump of the client was not aligned axially and render the prosthesis ineffective in walking straight. A universal joint compensator that could readjust the alignment of the stump/leg vertically was necessary and, therefore, an extra year was added to complete the project.

The lessons learned from the service-oriented project reflects what others reported [20]-[23] that engineer students need to interpret non-technical needs from client into technical constraints for the design. They learned about technique and sensibility associated with working with a disabled client. They learned about the importance of client's willingness and understanding to be the test subject. In addition, according to Grahame, Freeman, and Levi [18], students gain a better understanding of the community and become more open minded through service-learning. "They become better engineers."

\section{Future Work}


This was a pilot study to determine the practicality of implementing a multi-year multi-team iterative service-oriented project. The project was a success. Similar type of projects can be applied using the basic scaffold. Although the authors did not perform a formal assessment, overall impression and verbal feedback from students were that students welcomed this serviceoriented project as it was different from the traditional mechanical engineering project. Students also felt a sense of satisfaction by being able to help people with disability. Students were able to apply their knowledge learned from their curriculum to work on real life problem. For the future, it would be significant to formally obtain written reflections at the beginning and at the end of the project to assess the effectiveness of the communication system setup from one team to the next as well as the personal perceptions of service-learning. It would also be important to recruit the next team members before the departure of the current members so that more face-toface feedback would ensure faster start of the project for the follow-on group. It would provide valuable experience to the students if more clients could be recruited from the community.

\section{Acknowledgements}

The authors would like to thank the following ME students who participated in this project: Arlint, A., Durbin, T., Hayes, T.S., Jefferson, S., Jewett, S., Maltbie, J., Mihalec, B., Milne, S., Richards, T., Ward, M., and Willard, J..

\section{References}

[1] R. H. Todd, S. P. Magleby, C. D. Sorensen, B. R. Swan, and D.K. Anthony. "A survey of capstone engineering courses in North American," Journal of Engineering Education, vol. 84, pp.165-174, April 1995.

[2] A. J. Dutson, R. H. Todd, S. P. Magleby, and C. D. Sorensen. "A review of literature on teaching engineering design through project-oriented capstone courses," Journal of Engineering Education, vol. 86, pp.17-28, Jan. 1997.

[3] C. L. Dym, A. M. Agogino, O. Eris, D. D. Frey, and L. J. Leifer. "Engineering design thinking, teaching, and learning," Journal of Engineering Education, vol. 94, pp.103-120, Jan. 2005 .

[4] S, Howe, S. L. Poulos, and L. M. Rosenbauer. "The 2015 capstone design survey: observations form the front lines," Proceedings from ASEE's $123^{\text {rd }}$ Annual Conference \& Ecposition, New Orleans, LA, June 26-29, 2016. http://peer.asee.org/26085

[5] S. Howe, L. Rosenbauer, and S. Poulos. "The 2015 capstone design survey results: current practices and change over time," Journal of Engineering Education, vol. 33, pp.1393-1421, 2017.

[6] M. Lande and L. Leifer. "Introducing a "ways of thinking" framework for student engineers learning to do design," Proceedings of the 2009 ASEE Annual Conference \& Exposition, Austin, TX, June 14-17, 2009. https://peer.asee.org/5196 
[7] A. Cheville, "Designing successful design projects," Proceedings of the 2010 Annual Conference \& Exposition, Louisville, Kentucky, June 20-23, 2010. https://peer.asee.org/16783

[8] S. Owens, T. Morris, and G. Hall. "A multi-team multi-semester large-scale capstone project experience,' Proceedings of the 2012 ASEE Southeast Section Conference, Mississippi State University, Starkville, MS, April 1-3, 2012.

[9] O. Pierrakos, E. M. Barrella, R. L. Nagel, J. K. Nagel, J. J. Henriques, and D. D. Imholte. "An innovative two-year capstone design experience at James Madison University," Proceedings of the 120 th ASEE Annual Conference \& Exposition, Atlanta, GA, June 23-26, 2013. https://peer.asee.org/19190

[10] M. Johnson and J. L. Alvarado. "The use of an iterative industry project in a one semester capstone course," Proceedings of the $121^{\text {st }}$ ASEE Annual Conference \& Exposition, Indianapolis, IN, June 15-18, 2014. https://peer.asee.org/23183

[11] W. S. Reffeor and J. P. Farris. "An iterative approach to implementing sponsored design and build projects," Proceedings of the $122^{\text {nt }}$ ASEE Annual Conference \& Exposition, Seattle, WA, June 14-17, 2015. https://peer.asee.org/23541

[12] B. Aazhang, R. T. Abler, J. P. Allebach, L. F. Bost, J. R. Cavallaro, E. K. P. Chong, E. J. Coyle, J. B. S. Cullers, S. M. Dennis, Y. Dong, P. N. Enjeti, A. V. Filippas, J. E. Froyd, D. Garmire, J. George, B. E. Gilchrist, G. S. Hohner, W. L. Hughes, A. Johnson, C. Kim, H. Kim, R. H. Klenke, M. Z. Lagoudas, D. C. llewellyn, Y. Lu, K. J. Lybarger, S. marshall, S. Muralidharan, O. T. Ohta, F. R. Oretga, E. A. Riskin, D. M. Rizzo, T. J. Siller, J. SonnenbergKlein. S. M. Sadjadi, S. M. Srachan, M. Taheri, G. L. Woods, C. B. Zoltowski, B. C. Fabien, P. Johnson, R. Collins, and P. Murray. "Vertically integrated projects (VIP) programs: multidisciplinary projects with homes in any discipline," Proceedings of the 2017 ASEE Annual Conference \& Exposition, Columbys, OH, June 24-28, 2017. http://peer.asee.org/29103

[13] G. Bucks, W. Oakes, and J. Richardson. "Facilitating vertically integrated design teams," Proceedings of the 2009 ASEE Annual Conference \& Exposition, Austin, TX, June 14-17, 2009. https://peer.asee.org/5739

[14] M. Z. Lagoudas, and J. E. Froyd. "Multidisciplinary vertically integrated teams working on grand challenges," Proceedings of the 2017 ASEE Annual Conference \& Exposition, Columbus, OH, June 24-28, 2017. http://peer.asee.org/24515

[15] V. Gale and V. Bill. "Work in progress: multidisciplinary, vertically integrated projects course on 3-D printed biomedical devices," Proceedings of the 2019 ASEE Annual Conference \& Exposition, Tampa, FL, June 15-19, 2019. http://peer.asee.org/33641

[16] J. Bringardner. "Developing a vertically integrated project course to connect undergraduates to graduate research projects on smart cities transportation technology," Proceedings of the 2017 ASEE Annual Conference \& Exposition, Columbus, OH, June 24-28, 2017. http://peer.asee.org/281835 
[17] M. Poynter, S. Bansode, T. C. Dube, and J. Zhang. "Integration of SAE student competition with project course," Proceedings of the $126^{\text {th }}$ ASEE Annual Conference \& Exposition, Tampa, FL, June 15-19, 2019. https://peer.asee.org/32998

[18] K. S. Grahame, S. F. Freeman, and J. A. Levi. "Community engagement and service learning: putting faces to a community to create better engineers," Proceedings of the $126^{\text {th }}$ ASEE Annual Conference \& Exposition, Tampa, FL, June 15-19, 2019. https://peer.asee.org/32521

[19] S. M. Kellam, J. Stewart, D. C. Richter, B. M. Michaelis, and R. E. Gerlick. "An undergraduate engineering service learning project involving 3D-printed prosthetic hands for children," Proceedings of the $126^{\text {th }}$ ASEE Annual Conference \& Exposition, Tampa, FL, June 15-19, 2019. https://peer.asee.org/32085

[20] P. Bracken and J. D. Gibson. "Capstone design projects: helping the disabled," Proceedings of the 2002 ASEE Annual Conference \& Exposition, Montreal, Canada, June 16-19, 2002. http://peer.asee.org/10407

[21] P. Bracken and J. D. Gibson. "Service-learning in capstone projects: emphasizing reflection," Proceedings of the 2004 ASEE Annual Conference \& Exposition, Salt Lake City, Utah, June 20-23, 2004. https://peer.asee.org/13519

[22] D. Dekker, S. Sundarrao, and R. Dubey. "Capstone design courses: content recognition," Proceedings of the 2008 ASEE Annual Conference \& Exposition, Pittsburg, PA, June 22-25, 2008. https://peer.asee.org/4140

[23] J. Widmann, L. Slivovsky, B. Self, and J. K. Taylor. "Aligning goals of capstone design, service learning, and adapted physical activity," Proceedings of the 2009 ASEE Annual Conference \& Exposition, Austin, TX, June 14-17, 2009. https://peer.asee.org/4908

[24] G. McGimpsey and T. C. Bradford. "Limb Prosthetics Services and Devices_Unmet Need: Market Analysis, White Paper." http://www.nist.gov/tip/wp/pswp/publicly-submitted-whitepapers-healthcare. Published 2011-08-02. [Accessed Jan 21, 2016].

[25] G. E. Reiber, L. V. McFarland, S. Hubbard, C. Maynard, D. K. Blough, J. M. Gambel, and D. G. Smith. "Service members and veterans with major traumatic limb loss from Vietnam War and OIF/OEF Conflicts: Survey methods, Participants, and Summary Findings," Journal of Rehabititation Research \& Development, vol 47, pp. 275-298, 2010.

[26] ABET, Abet Criteria for Accrediting Engineering Programs, 2020 - 2021. Retrieved from https://www.abet.org/accreditation/accreditation-criteria/criteria-for-accrediting-engineeringprograms-2020-2021/. [Accessed Jan 21, 2020]. 
[27] G. Colombo, S. Gabbiadini, D. Regazzoni, and C. Rizzi. "Design Procedure and Rules to Configure Lower Limb Prosthesis," Proceedings of the ASME 2011 International Design Engineering Technical Conferences \& Computers and Information in Engineering Conference, Washington, DC, August 28-31, 2011. 